\title{
MSPD PROCEDURE COMBINED WITH GC-MS FOR THE DETERMINATION OF PROCYMIDONE, BIFENTHRIN, MALATHION AND PIRIMICARB IN HONEY
}

\author{
Débora Santos Silva Bezerra, Marcell Mendes Santos Silva, Pedro Henrique Viana de Carvalho, Adriano Aquino e \\ Sandro Navickiene* \\ Departamento de Química, Universidade Federal de Sergipe, Av. Mal. Rondon, s/n, 49100-000 São Cristóvão - SE, Brasil
}

Recebido em 19/11/09; aceito em 22/2/10; publicado na web em 10/6/10

\begin{abstract}
A method based on matrix solid-phase dispersion and gas chromatography-mass spectrometry to determine procymidone, malathion, bifenthrin and pirimicarb in honey is described. The best results were obtained using $1.0 \mathrm{~g}$ of honey, $1.0 \mathrm{~g}$ of silica-gel as dispersant sorbent and acetonitrile as eluting solvent. The method was validated by fortified honey samples at three concentration levels $(0.2,0.5$ to $1.0 \mathrm{mg} \mathrm{kg}$ $\left.{ }^{1}\right)$. Average recoveries $(\mathrm{n}=7)$ ranged from 54 to $84 \%$, with relative standard deviations between 3.7 and $8.5 \%$. Detection and quantification limits attained by the developed method ranged from 0.02 to $0.08 \mathrm{mg} \mathrm{kg}^{-1}$ and 0.07 to $0.25 \mathrm{mg} \mathrm{kg}^{-1}$ for the honey, respectively.
\end{abstract}

Keywords: honey; pesticides; matrix solid-phase dispersion.

\section{INTRODUCTION}

Pesticide residues in honey can originate from the contamination of plants where bees collect pollen and nectar or from the treatment of beehives to control some pests and diseases they suffer. ${ }^{1}$ Contaminants can remain in the apiarian products and constitute a health risk because of their toxicity. ${ }^{2}$ Besides, different products, like that procymidone, malathion, pirimicarb and bifenthrin, are used to control phytophagous insects and fungal pathogens on a variety of crops in the Northeastern part of the Brazil. When applied, they can be transferred to the apiaries. Therefore, monitoring of pesticide residues in honey is of particular concern to consumer safety. The literature describes several chromatographic methods for the determination of pesticide residues in honey. ${ }^{3}$ Most of the published methods involve liquidliquid extraction (LLE) followed by a clean up step, ${ }^{4}$ supercritical fluid extraction (SFE), ${ }^{5}$ solid-phase extraction (SPE), ${ }^{6}$ solid-phase microextraction (SPME), ${ }^{7,8}$ or stir bar sorptive extraction (SBSE). ${ }^{9}$ To our knowledge, there are only two publications describing the use of matrix solid-phase dispersion (MSPD) procedure for the extraction of compounds belonging to different chemical classes, mainly pyrethroids, organochlorines, organophosphorus or acaricides, from honey. ${ }^{10,11}$ Besides, none of the published papers have reported the simultaneous analysis of pirimicarb, malathion, bifenthrin and procymidone in honey using MSPD method. MSPD is a sample preparation method that comprises sample homogenization, extraction and clean up and requires only a small sample size and small amounts of solvent. ${ }^{12}$ It avoids the drawbacks generally associated with liquid-liquid extraction, such as the use of large volumes of solvent, the occurrence of troublesome emulsions, and slow speed. ${ }^{13}$ The method involves blending a sample with a solid support isolating organic compounds by adsorbing them on the suitable solid adsorbents followed by desorption with a small amount of organic solvent. ${ }^{14}$ Thus, MSPD is an analytical technique used for extraction of compounds from solid and viscous samples. ${ }^{15,16}$

The work aimed at developing a simple method for the determination of pirimicarb, malathion, bifenthrin and procymidone in honey samples using matrix solid-phase dispersion and gas chromatographymass spectrometry. Figure 1 shows the molecular structure of the pesticides studied.

\footnotetext{
*e-mail: sandnavi@ufs.br
}

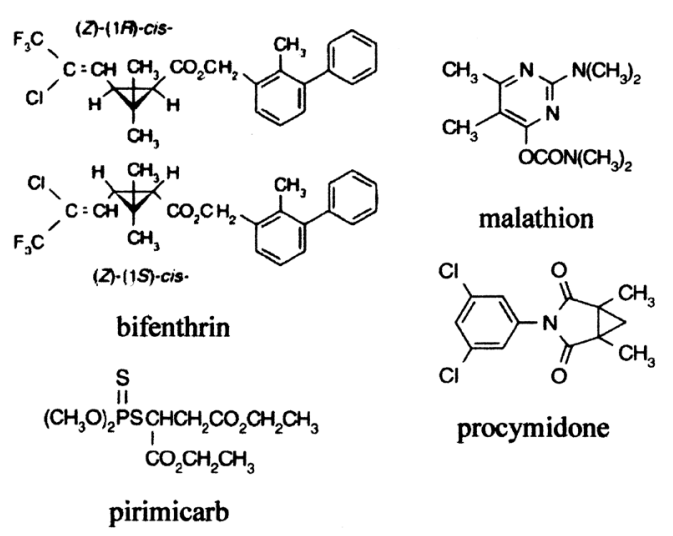

Figure 1. Chemical structures of the pesticides studied

\section{EXPERIMENTAL}

\section{Reagents and chemicals}

Certified standards of procymidone, bifenthrin, malathion and pirimicarb were purchased from Dr. Ehrenstorfer (Augsburg, Germany). All standards were at least $98.5 \%$ pure. Dichloromethane, acetone, acetonitrile, ethyl acetate and $n$-hexane were Nanograde ${ }^{\circledR}$ (Mallinckrodt Baker, Paris, KY, USA). Analytical grade anhydrous sodium sulfate was supplied from Mallinckrodt Baker (Paris, KY, USA). Research grade Florisil (80-100 mesh) was supplied from Sigma (Büchs, Switzerland), $\mathrm{C}_{18}$-bonded silica $(50 \mu \mathrm{m})$ was obtained from Phenomenex (Torrance, CA, USA), silica-gel 60 (70-230 mesh) from Merck (Darmstadt, Germany), neutral alumina (70-290 mesh, activity I) from Macherey-Nagel (Düren, Germany).

\section{Standard solution preparation}

A stock standard solution $\left(400 \mu \mathrm{g} \mathrm{mL}^{-1}\right)$ of each pesticide was prepared by dissolving $20 \mathrm{mg}$ of the pure analytical standard in 50 $\mathrm{mL}$ of dichloromethane. A pesticide intermediate standard solution was prepared by transferring $1 \mathrm{~mL}$ from each pesticide to a 100 $\mathrm{mL}$ volumetric flask and diluting to volume with dichloromethane to obtain a concentration of $40 \mu \mathrm{g} \mathrm{mL} \mathrm{m}^{-1}$. To prevent matrix effects 
that might result in an over or under recovery estimations, working standard solutions were prepared in extracts obtained after MSPD from pesticide-free honey samples at concentrations from 0.05 to 10 $\mu \mathrm{g} \mathrm{mL} \mathrm{m}^{-1}$. Stock standard and working solutions were stored at $-18^{\circ} \mathrm{C}$.

\section{Instrumentation and chromatographic conditions}

A Shimadzu GC-2010 gas chromatograph with a QP-2010plus mass spectrometer (Kyoto, Japan) was used. The GC system, with an electronic flow control (EFC), was equipped with a Shimadzu 2010 autosampler and a split/splitless injection port. Chromatographic separation was performed on a fused-silica column RTx5MS (5\% phenyl-95\% polydimethylsiloxane; $30 \mathrm{~m} \times 0.25 \mathrm{~mm}$ ID, $0.25 \mu \mathrm{m}$ ) supplied by Restek (Bellefonte, PA, USA). Helium (purity 99.995\%) was used as carrier gas at a constant flow-rate of $1.5 \mathrm{~mL} \mathrm{~min}^{-1}$, and was previously passed through hydrocarbon and moisture traps. The column temperature was programmed as follows: $60{ }^{\circ} \mathrm{C}$ for $1.5 \mathrm{~min}$, then directly to $300{ }^{\circ} \mathrm{C}$ at $9{ }^{\circ} \mathrm{C} \mathrm{min}{ }^{-1}$. The solvent delay was $5 \mathrm{~min}$. The total analysis time was 28 min and the equilibrium time was $3 \mathrm{~min}$. The injection port was maintained at $250{ }^{\circ} \mathrm{C}$ and $1 \mu \mathrm{L}$ sample volumes were injected in splitless mode $(50 \mathrm{~s})$. The data were acquired and processed using Shimadzu GC Solution software. The eluent from the GC column was transferred via a transfer line heated at $280{ }^{\circ} \mathrm{C}$ and fed into a $70 \mathrm{eV}$ electron impact ionization source, also maintained at $280^{\circ} \mathrm{C}$. The target abundances were determined by injection of individual pesticide standards under the same chromatographic conditions using full scan mode with the mass/charge ratio ranging of the $\mathrm{m} / \mathrm{z}, 60$ to 500. In these evaluations, the characteristic ions were chosen, and the MS system was then programmed in selective ion monitoring (SIM) mode for quantification of each pesticide. The choice of the ions for SIM acquisition was based on the best $\mathrm{S} / \mathrm{N}$ ratios. The ions were divided into two groups that were recorded sequentially during the injection, on the basis of the retention times of the single compounds. For the first acquisition window (5.00 to $20.00 \mathrm{~min}$ ), the ions monitored were $\mathrm{m} / \mathrm{z}, 72,166$ and 238 (pirimicarb), $m / z, 93,127$ and 256 (malathion), $m / z, 96,186$ and 283 (procymidone). For the second acquisition window (20.00 to $27.00 \mathrm{~min}$ ) $\mathrm{m} / \mathrm{z}, 165,181$ and $\mathbf{3 4 2}$ (bifenthrin) were monitored. Values of $\mathrm{m} / \mathrm{z}$ in bold type correspond to the quantification ion for each analyte.

\section{Matrix effect evaluation}

Matrix components can provide variations in the response of the detector to pesticides. So, the matrix effect was evaluated by comparing the detector response with regards to the pesticide standards prepared in dichloromethane to pesticide standards prepared in blank honey extract. When standards were prepared by spiking blank honey samples with known amounts of pesticides, higher peak areas were obtained from the same pesticide concentrations. This can be explained by a matrix effect that improves transfer of analytes from the injection port to the column and enhances the chromatographic response of pesticides. ${ }^{17-19}$ Consequently, the quantification of pesticide residues was carried out through matrix-matched standards.

\section{Sample preparation and fortification}

The honey samples were taken from hives at the Tapipi Apiary located in the city of Santo Amaro das Brotas, state of Sergipe, Brazil. Samples were collected in November 2007. These samples, weighing between 300 and $500 \mathrm{~g}$, were stored in their original containers, at $10{ }^{\circ} \mathrm{C}$, in a dark place, until analysis.
For the preparation of fortified samples, a volume of $500 \mu \mathrm{L}$ of different standard working solutions $\left(0.4,1.0\right.$ and $\left.2.0 \mu \mathrm{g} \mathrm{mL}^{-1}\right)$ was added to $1.0 \mathrm{~g}$ of honey sample resulting in the levels of $0.2,0.5$ and $1.0 \mathrm{mg} \mathrm{kg}^{-1}$. The spiked sample was allowed to stand at room temperature for a $30 \mathrm{~min}$, and it was homogenized at regular intervals (10 min) before extraction. Each fortification level was analyzed through seven replicates. The extraction procedure described below was followed.

\section{Extraction procedure}

A representative portion of the honey $(1.0 \mathrm{~g})$ was placed into a glass mortar $(\mathrm{ca} .50 \mathrm{~mL})$ and $1.0 \mathrm{~g}$ of silica-gel was added. The honey was then gently blended into the silica-gel material with a glass pestle, until a homogeneous mixture was obtained (ca. $3 \mathrm{~min}$ ). The homogenized mixture was introduced into a 100 x $20 \mathrm{~mm}$ ID polypropylene column filled with $0.1 \mathrm{~g}$ of silanized glass-wool at the bottom and $1.0 \mathrm{~g}$ of anhydrous $\mathrm{Na}_{2} \mathrm{SO}_{4}$, respectively. The pesticides were eluted with $10 \mathrm{~mL}$ portion of acetonitrile that was allowed to elute dropwise by applying a slight vacuum. The eluent was collected into a graduated conical tube and concentrated to a volume of $1 \mathrm{~mL}$, using first a rotary vacuum evaporator $\left(45^{\circ} \mathrm{C}\right)$, followed by a gentle flow of nitrogen. A $1 \mu \mathrm{L}$ portion of the extract was then directly analyzed by GC-MS system.

\section{RESULTS AND DISCUSSION}

\section{GC-MS conditions}

Pesticide residues were determined by GC-MS-SIM. The gaschromatographic conditions allow a good resolution of the pesticides in 28 min using a fused-silica column RTx-5MS (5\% phenyl-95\% polydimethylsiloxane; $30 \mathrm{~m}$ x $0.25 \mathrm{~mm} \mathrm{ID}, 0.25 \mu \mathrm{m})$. Chromatograms obtained of a standard mixture solution in dichloromethane at $0.2 \mathrm{mg} \mathrm{kg}^{-1}$ and of a standard mixture solution in a blank honey sample after MSPD at the same concentration level are illustrated in Figure 2, together with a chromatogram of the honey control sample, demonstrating the selectivity of the MSPD method developed.

\section{MSPD procedure}

The extraction method proposed was based on a previous procedure established for the determination of buprofezin, vinclozolin, tetradifon and bifenthrin in propolis. ${ }^{20}$ The most suitable extraction parameters were evaluated to achieve the highest recovery for pirimicarb, malathion, procymidone and bifenthrin from honey. The type of the sorbent and the polarity of the elution solvent are known to be key factors in MSPD, since they determine both the efficiency of the extraction and the purity of the final extracts. ${ }^{21}$ Preliminary investigations for optimization of the MSPD procedure for the extraction of pesticides from honey matrix were performed using samples spiked with pesticide standard solution at $0.5 \mathrm{mg} \mathrm{kg}^{-1}$, and $\mathrm{C}_{18}$, neutral alumina, silica-gel or Florisil as solid-phase sorbent. Ethyl acetate was the eluting solvent, and the solid-phase:honey matrix proportion $(1: 1, w / w)$. When comparing the data obtained, rather different results were found for the sorbents tested. The extraction column prepared with silica-gel:honey matrix blend produced an extract that shows minimal interferences for most of the pesticides studied, while the use of $\mathrm{C}_{18}$ or neutral alumina as support for MSPD method produces highest recoveries (> 120\%) similar to those obtained with Florisil, considering the same proportion between solid-phase and honey matrix. In addition, different silica-gel:honey matrix ratios (1:2 and $2: 1, w / w)$ were attempted to optimize the MSPD method. The results obtained show that the best recoveries were obtained using $1.0 \mathrm{~g}$ of 


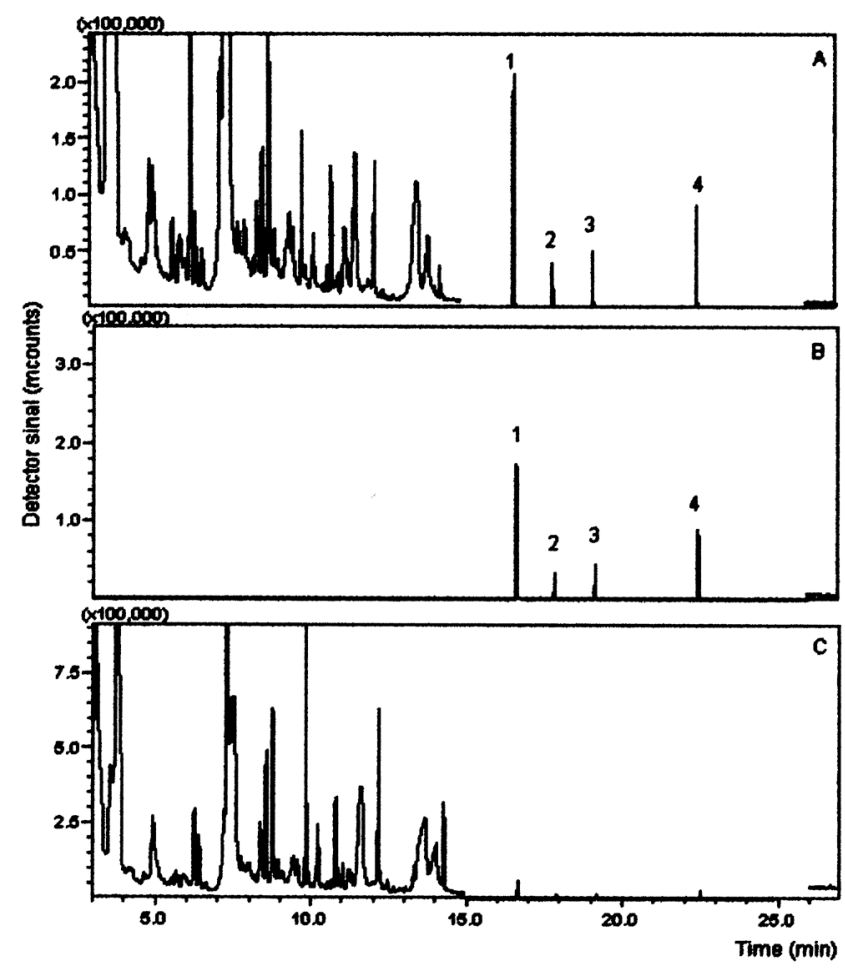

Figure 2. GC-MS chromatograms of (A) standard mixture solution at a concentration level of $0.2 \mathrm{mg} \mathrm{kg}^{-1}$, using $1.0 \mathrm{~g}$ of honey $+1.0 \mathrm{~g}$ of silica-gel and acetonitrile $(20 \mathrm{~mL}) ;(B)$ standard mixture solution in dichloromethane at 0.2 $m g \mathrm{~kg}^{-1}$, and $(C)$ honey control sample. The numbered peaks are as follows: 1-pirimicarb; 2-malathion; 3-procymidone; 4- bifenthrin

silica-gel:1.0 g of honey matrix (1:1, w/w). Moreover, an increase in the silica-gel amount did not improve the recovery of the pesticides studied. Furthermore, other solvents were tested (acetone, acetonitrile and $n$-hexane:ethyl acetate $(1: 4, \mathrm{v} / \mathrm{v}))$ for each system, using different solvent volumes $(20,30$ and $40 \mathrm{~mL})$. The best results were obtained with $20 \mathrm{~mL}$ of acetonitrile, because recovery increased slowly with increasing eluent volume ( 30 or $40 \mathrm{~mL}$ ). All analyses were carried out in duplicate. Table 1 shows the influence of different eluting solvent on pesticide recoveries. Based on these overall results, the combined effect of silica-gel as solid-phase and acetonitrile as elution solvent makes this extraction procedure suitable for determining pirimicarb, malathion, procymidone and bifenthrin in a complex matrix such as honey. Once the factors that affect the MSPD procedure had been optimized, validation of the method was performed.

\section{Recovery study}

The concentration of each compound in honey samples was determined by comparing the peak areas obtained in samples with those found in standards. Chromatographic standards were prepared by spiking blank samples with known amounts of pesticides. The untreated honey was fortified at 3 different concentrations $(0.20$, 0.50 and $1.0 \mathrm{mg} \mathrm{kg}^{-1}$ ). Standard solutions were injected after every ten samples with automatic injection to monitor changes in chromatographic conditions, and the relative standard deviation values obtained for the retention times ranged from 0.06 to $0.09 \%$, whereas for relative peak areas the values ranged from 2.8 to $8.0 \%$. Therefore, the repeatability achieved in these chromatographic conditions is very good. Fortification levels were selected to reach the maximum residue levels (MRLs) established by the European Union legislation values, which range from 0.2 to $1.0 \mathrm{mg} \mathrm{kg}^{-1}$ for three acaricides in
Table 1. Influence of different eluting solvents and silica-gel as solid-phase sorbent on pesticide recovery in the MSPD procedure using $1.0 \mathrm{~g}$ of honey + $1.0 \mathrm{~g}$ of sorbent. Honey sample fortified at $0.5 \mathrm{mg} \mathrm{kg}^{-1}$

\begin{tabular}{|c|c|c|c|c|c|c|c|c|c|c|}
\hline \multirow{4}{*}{ Pesticide } & \multirow{4}{*}{$\begin{array}{l}\text { silica- } \\
\text { gel: } \\
\text { honey } \\
\text { (w/w) }\end{array}$} & \multicolumn{9}{|c|}{ Recovery $(\%), 0.5 \mathrm{mg} \mathrm{kg}^{-1}(\mathrm{n}=2)$} \\
\hline & & \multirow{2}{*}{\multicolumn{3}{|c|}{ acetone }} & \multirow{2}{*}{\multicolumn{3}{|c|}{ uting solvent $(1$}} & \multirow{2}{*}{\multicolumn{3}{|c|}{$\begin{array}{l}\text { L) } \\
\text { n-hexane: } \\
\text { ethyl acetate } \\
(1: 4, v / v)\end{array}$}} \\
\hline & & & & & & & & & & \\
\hline & & 20 & 30 & 40 & 20 & 30 & 40 & 20 & 30 & 40 \\
\hline \multirow[t]{3}{*}{ pirimicarb } & $1: 1$ & 34 & 44 & 54 & 69 & 64 & 74 & 126 & 144 & 204 \\
\hline & $1: 2$ & 38 & 42 & 37 & 58 & 49 & 54 & 110 & 132 & 160 \\
\hline & $2: 1$ & 40 & 38 & 40 & 55 & 49 & 50 & 112 & 129 & 140 \\
\hline \multirow[t]{3}{*}{ procymidone } & $1: 1$ & 58 & 42 & 58 & 72 & 68 & 70 & 165 & 158 & 158 \\
\hline & $1: 2$ & 47 & 39 & 44 & 68 & 71 & 75 & 122 & 119 & 130 \\
\hline & $2: 1$ & 44 & 36 & 42 & 68 & 68 & 72 & 125 & 123 & 128 \\
\hline \multirow[t]{3}{*}{ malathion } & $1: 1$ & 65 & 55 & 10 & 74 & 75 & 78 & 221 & 165 & 220 \\
\hline & $1: 2$ & 55 & 45 & 65 & 65 & 65 & 75 & 180 & 175 & 165 \\
\hline & $2: 1$ & 48 & 42 & 50 & 63 & 70 & 71 & 120 & 110 & 154 \\
\hline \multirow[t]{3}{*}{ bifenthrin } & $1: 1$ & 38 & 48 & 38 & 62 & 63 & 63 & 138 & 142 & 145 \\
\hline & $1: 2$ & 40 & 40 & 46 & 59 & 52 & 52 & 108 & 119 & 137 \\
\hline & $2: 1$ & 36 & 36 & 40 & 42 & 44 & 44 & 119 & 125 & 145 \\
\hline
\end{tabular}

honey, since the maximum limits of pesticide residues in honey are not established in the national regulations. ${ }^{22}$ The results of the average recoveries ranging from 54 to $84 \%$, with relative standard deviations (RSD) values of 3.7 to $8.5 \%$, as can be seen on Table 2. Each recovery analysis was repeated seven times. The precision and accuracy were considered adequate for validating the method according to the validation criteria. ${ }^{23}$ Accuracy was calculated as the percent ratio between the found and the known concentrations and precision was determined as the percentage in relative standard deviation (\%RSD), which is calculated by dividing the standard deviation for a series of measurements by the mean of the same sets of measurements and multiplying by 100 . The repeatability and intermediate precision of the extraction procedure were estimated analyzing five aliquots of spiked honey sample $\left(0.5 \mathrm{mg} \mathrm{kg}^{-1}\right)$ each day, and during 5 days. The RSD values within and between days were below 12 and $18 \%$, respectively, which is considered to be acceptable given the difficulty of analyzing these compounds in honey samples.

\section{Linearity, and detection and quantification limits}

The detector response was linear within the concentration range studied. The linearity for all compounds was determined using blank honey samples fortified at eight concentration levels $(0.05,0.15,0.25$, $0.50,1.0,2.5,5.0$, and $\left.10.0 \mu \mathrm{g} \mathrm{mL}^{-1}\right)$. At each analyte amount, two replicate measurements were made. The slope and intercept values, together with their standard deviations, were determined using applying regression analyses. Linear regression coefficients for all pesticides ranged from 0.9961 to 0.9986 .

The limits of detection (LOD) for the pesticides studied ranged from 0.02 to $0.08 \mathrm{mg} \mathrm{kg}^{-1}$, which were calculated considering the standard deviation of noise (a value of 7 times the standard deviation of the blank) and the slope of the regression line. The limits of quantification (LOQ) were determined as the lowest concentration giving a response of tentimes the average of the baseline noise defined from seven unfortified samples. So, the LOQ values for these compounds ranged from 0.07 to $0.25 \mathrm{mg} \mathrm{kg}^{-1} \cdot{ }^{23,24}$ Table 3 summarizes these data of the pesticide studied.

\section{Real samples}

The MSPD procedure was applied to determine the pesticides selected in honey samples. Four different samples of honey taken 
Table 2. Percentage recoveries and relative standard deviations obtained by MSPD procedure of the fortified honey for the pesticides studied $(n=7)^{*}$

\begin{tabular}{lccc}
\hline Pesticide & $\begin{array}{c}\text { Spike level } \\
\left(\mathrm{mg} \mathrm{kg}^{-1}\right)\end{array}$ & $\begin{array}{c}\text { Average recovery } \\
(\%)^{*}\end{array}$ & $\begin{array}{c}\text { RSD } \\
(\%)\end{array}$ \\
\hline pirimicarb & 0.20 & 75 & 6.7 \\
& 0.50 & 65 & 5.0 \\
malathion & 1.00 & 76 & 3.7 \\
& 0.20 & 77 & 8.5 \\
procymidone & 0.50 & 66 & 6.2 \\
& 1.00 & 84 & 4.4 \\
& 0.20 & 79 & 4.1 \\
bifenthrin & 0.50 & 69 & 6.7 \\
& 1.00 & 84 & 4.0 \\
& 0.20 & 61 & 7.1 \\
& 0.50 & 54 & 7.1 \\
& 1.00 & 63 & 7.4 \\
\hline
\end{tabular}

Table 3. Retention times, calibration data, LOD and LOQ of the pesticides analysed by GC-MS

\begin{tabular}{lccccc}
\hline Pesticide & $\begin{array}{c}\text { Retention } \\
\text { time } \\
(\mathrm{min})\end{array}$ & \multicolumn{2}{c}{ Calibration data } & & \\
& 16.7 & $\mathrm{y}=406402 \mathrm{x}+8326$ & 0.9995 & 0.02 & 0.07 \\
pirimicarb & 18.1 & $\mathrm{y}=78659 \mathrm{x}-734$ & 0.9986 & 0.03 & 0.11 \\
malathion & 19.4 & $\mathrm{y}=109836 \mathrm{x}+5143$ & 0.9998 & 0.08 & 0.25 \\
procymidone & 22.8 & $\mathrm{y}=220213 \mathrm{x}-8804$ & 0.9992 & 0.04 & 0.08 \\
bifenthrin & & & & & $\begin{array}{c}\text { LOQ } \\
\text { coefficient }\end{array}$ \\
\hline
\end{tabular}

from a local market were analyzed using this procedure. No pesticide residues, at concentrations above the detection limit, were found in these samples.

\section{CONCLUSIONS}

The proposed MSPD procedure followed by GC/MS in the SIM mode can be applied to determine pirimicarb, malathion, procymidone and bifenthrin in honey. The method uses a silica-based-gel on the MSPD column and acetonitrile as elution solvent. Acceptable recoveries for pesticides $\geq 61 \%$ were obtained, except for bifenthrin $(54 \%)$ in honey. The results demonstrate that the accuracy, precision and selectivity of the proposed method are satisfactory for multi-residue analyses of pesticides. Besides, the method requires a small sample size and offers considerable savings in terms of solvent consumption, cost of materials, sample manipulation and analysis time. The limits of detection and quantification ranged from 0.02 to $0.08 \mathrm{mg} \mathrm{kg}^{-1}$ and 0.07 to $0.25 \mathrm{mg} \mathrm{kg}^{-1}$ for the honey, respectively.

\section{ACKNOWLEDGEMENTS}

The authors wish to thank CNPq/MCT (process n ${ }^{\circ}: 350073 / 2004-$ 0 ) and FAPITEC-SE/FUNTEC for fellowship and financial support of this study.

\section{REFERENCES}

1. Albero, B.; Sánchez-Brunete, C.; Tadeo, J. L.; J. Agric. Food Chem. 2004, 52, 5828 .

2. Bogdanov, S.; Apidologie 2006, 37, 1.

3. Rial-Otero, R.; Gaspar, E. M.; Muora, I.; Capelo, J. L.; Talanta 2007, 71, 503.

4. Fernández, M.; Picò, Y.; Mañes, J.; J. Food Protec. 2002, 65, 1502.

5. Rissato, S. R.; Galhiane, M. S.; Knoll, F. R. N.; Apon, B. M.; J. Chromatogr., A 2004, 1048, 153.

6. Tadeo, J. L.; Albero, B.; Sánchez-Brunete, C.; J. Agric. Food Chem. 2004, 52, 5828 .

7. Jiménez, J. J.; Bernal, J. L.; Nozal, M. J.; Toribio, L.; Martin, M. T.; J. Chromatogr., A 1998, 823, 381.

8. Picó, Y.; Fernández, M.; Ruiz, M. J.; Font, G.; J. Biochem. Biophys. Meth. 2007, 70, 117.

9. Blasco, C.; Fernández, M.; Picó, Y.; Font, G.; J. Chromatogr., A 2004, $1030,77$.

10. Albero, B.; Sánchez-Brunete, C.; Tadeo, J. L.; J. AOAC Int. 2001, 84, 1165.

11. Sánchez-Brunete, C.; Albero, B.; Miguel, E.; Tadeo, J. L.; J. AOAC Int. 2002, 85, 128.

12. Valsamaki, V. I.; Boti, V. I.; Sakkas, V. A.; Albanis, T. A.; Anal. Chim. Acta 2006, 573-574, 195.

13. Poole, C. F.; J. Chromatogr., A 2007, 1158, 241.

14. Barker, S. A.; J. Biochem. Biophys. Meth. 2007, 70, 151.

15. Silva, M. G. D.; Aquino, A.; Dórea, H. S.; Navickiene, S.; Talanta 2008, 76,680 .

16. Carvalho, P. H. V.; Barreto, A. S.; Rodrigues, M. O.; Mesquita, M. E.; Alves Júnior, S.; Prata, V. M.; Alves, P. B.; Navickiene, S.; J. Sep. Sci. 2009, 32, 2132.

17. Frenich, A. G.; Vidal, J. L. M.; Moreno, J. L. F.; Romero-González, R.; J. Chromatogr., A 2009, 1216, 4798.

18. Pinho, G. P.; Neves, A. A.; Queiroz, M. L. R.; Silvério, F. O.; Quim. Nova 2009, 32, 987.

19. Freitas, S. S.; Lanças, F. M.; J. Sep. Sci. 2009, 32, 3698.

20. Santos, T. F. S.; Aquino, A.; Dórea, H. S.; Navickiene, S.; Anal. Bioanal. Chem. 2008, 390, 1425 .

21. Boglialli, S.; Di Corsia, A.; J. Biochem. Biophys. Meth. 2007, 70, 163.

22. European Commission Regulation; Document no. 239/1999, Brussels, 12 November 1999.

23. European Commission, DG-SANCO, Method validation and quality control procedures for pesticide residues analysis, Document no. SANCO/10232/2006, Brussels, 24 March 2006.

24. Bliesner, D. M.; Validating Chromatographic Methods - A Practical Guide, $1^{\text {st }}$ ed.; Wiley: New Jersey, 2006. 